\title{
Training Primary Care Physicians to Serve Underserved Communities: Follow-up Survey of Primary Care Graduates
}

Lisa Altshuler, $P h D^{7}$, Harriet Fisher, $B A^{7}$, Kathleen Hanley, $M D^{7}$, Jasmine Ross, $B A^{2}$,

Sondra Zabar, $M D^{7}$, Jennifer Adams, $M D^{7}$, and Mack Lipkin, MD ${ }^{7}$

'Department of Medicine, New York University School of Medicine, New York, NY, USA; ${ }^{2}$ Department of Pediatrics, New York University School of Medicine, New York, NY, USA.

$\mathrm{J}$ Gen Intern Med 34(12):2728-30

DOI: $10.1007 / \mathrm{s} 11606-019-05198-x$

(C) Society of General Internal Medicine 2019

I ncreasing proportions of primary care (PC) physicians enhance population life expectancy and quality of life. ${ }^{1}$ Basu et al. found that "... as the density of primary care physicians decreased from 46.6 to 41.4 per 100,000 population" mortality increased. ${ }^{2}$ For the underserved, need for PCPs is higher, supply is worse, and attrition is greater due to burnout and leaving practice. ${ }^{3}$ Thus, effective training programs are necessary to prepare competent, committed, resilient doctors to practice PC, particularly with underserved communities.

Our prior, 2006, survey of 20 years of graduates from the NYU/Bellevue Primary Care Internal Medicine Residency (NYUBPC) concluded that program graduates' high engagement in PC (over 90\%) and unexpectedly low (15\%) burnout relate to our program pillars: psychosocial medicine, clinical epidemiology, health policy, learning to learn and teach, being whole (patients and learners), and visioning-layered over rigorous inner-city clinical training. ${ }^{4}$

This report provides data on the subsequent 7 years of graduates to ascertain whether favorable outcomes persist in the new high-pressure primary care environment. We assessed the impact of NYUBPC on residents' graduate career choices, values, and style and elicited reflections concerning complexities of educating primary care physicians.

\section{METHODS}

We sent an anonymous, web-based, 44-item, IRB-approved survey, including 12 open-ended questions about career path and reflections on residency training experiences, to all graduates (56) of the NYUBPC from 2007 to 2014. We summarized current practice and general perceptions of training with

Received April 23, 2019

Accepted July 9, 2019

Published online July 24, 2019 descriptive statistics and analyzed and summarized the content of text iteratively by two readers (LA, ML).

\section{RESULTS}

We received 37/56 (66\%) responses. Respondents averaged 5 years past residency (sd, 2.4). Eighty-nine percent practice PC. Seventy percent work with underserved populations. Eighty-five percent endorse PC as a career choice. Ninetytwo percent agree or strongly agree their life is balanced. Six percent reported burnout. Seventy-four percent feel prepared for PC practice, rating as essential intense psychosocial medicine training, safety net hospital inpatient training, learning to teach and learn, and clinical epidemiology training (Table 1). Seventy percent of respondents have mentors. Personal connections with patients, peers and co-workers, and faculty were rated key. Open-text responses identify the program's focus on the whole patient and its strong community support for trainees as essential to developing their skills and resilience against difficulties (see Table 2). Since graduating, alumni report struggling with the mismatch between the ideal PC they strive towards and the difficult pressures of time, productivity, and quality measures. They feel equally or more prepared for challenges of practice than colleagues trained elsewhere. While they anticipate an evolving PC landscape, they feel the program taught them essentials needed to adapt to changing circumstances.

\section{DISCUSSION}

While our graduates self-report that they are prepared for and committed to careers in PC for the underserved, they still suffer the slings and arrows of primary care today. In the rapidly evolving crunch of primary care needs and systems, our graduates recognized the challenges but felt equipped with skills and attitudes of resilient providers of primary care and educators.

Whereas mid-career doctors have the highest levels of "burnout" (53.9\%), only $6 \%$ of ours reported burnout. ${ }^{5}$ We believe but cannot prove that our focus on longitudinally reinforced psychosocial training, a rigorous skills and clinical reasoning-focused curriculum, role modeling, care of the underserved, and strong social support from faculty and peers 
Table 1 Current Practice and Related Essential Training Experiences

\begin{tabular}{|c|c|}
\hline & Percentage \\
\hline \multicolumn{2}{|c|}{ Components of training considered essential to professional development (rating of 4 on 4-point Likert scale) } \\
\hline Patient care in primary care setting & $90 \%$ \\
\hline Psychosocial medicine & $83 \%$ \\
\hline Inpatient training at city safety net hospital & $83 \%$ \\
\hline Resident-led conferences (with resident selecting topic) & $73 \%$ \\
\hline Learning to teach & $65 \%$ \\
\hline Clinical epidemiology & $48 \%$ \\
\hline \multicolumn{2}{|l|}{ Current practice (\% endorsing each item) } \\
\hline Practice in primary care setting & 89 \\
\hline Average time per week spent in clinical work & $66 \%$ (range, $0-100 \%$ ) \\
\hline Underserved patients in their practices & $70 \%$ \\
\hline Clinic atmosphere is hectic/chaotic (4 or 5 on 5 -point Likert scale) & $53 \%$ \\
\hline Felt prepared for the challenges of primary care & $74 \%$ \\
\hline Agree or strongly agree with primary care as career choice ( 3 or 4 on 4 -point Likert scale) & $85 \%$ \\
\hline Agree or strongly agree that their "life is balanced" ( 3 or 4 on a 4-point Likert scale) & $92 \%$ \\
\hline Report persistent symptoms of burnout ( 4 or 5 on a 5 -point Likert scale) & $6 \%$ \\
\hline
\end{tabular}

provides our trainees with the resilience required in under resourced systems with underserved communities. However, as $44 \%$ did not respond, they may be struggling more or less resilient.

Training program transformations are necessary but not sufficient components of the complex changes needed to ensure well-prepared PC doctors join and stay in practice in high-need communities. Indeed, our residents report challenges to purity of practice, continuity of care, and opportunities for advocacy. As our country faces a debilitating shortage of PC doctors, a multifaceted approach to supporting their professional development and success is paramount. Programs must evolve to ensure that residents have essential skills for doctors and systems to thrive in a challenging health care environment.
Corresponding Author: Harriet Fisher, BA; Department of Medicine New York University School of Medicine, 550 First Avenue, BCD D401, New York, NY 10016, USA (e-mail: Harriet.Fisher@nyulangone. org).

\section{Compliance with Ethical Standards:}

Conflict of Interest: The authors declare that they do not have a conflict of interest.

\section{REFERENCES}

1. Starfield B, Shi L, Macinko J. Contribution of primary care to health systems and health. The Milbank quarterly. 2005;83(3):457-502. https:// doi.org/10.1111/j.1468-0009.2005.00409.x

2. Basu S, Berkowitz SA, Phillips RL, Bitton A, Landon BE, Phillips RS. Association of Primary Care Physician Supply With Population Mortality in the United States, 2005-2015Association of US Primary Care Physician Supply and Population MortalityAssociation of US Primary Care Physician

Table 2 Open-ended Responses About Impact of Training on Current Practice

\begin{tabular}{|c|c|}
\hline Theme & Resident quotes \\
\hline $\begin{array}{l}\text { Residency shapes complex } \\
\text { understanding of patient need }\end{array}$ & $\begin{array}{l}\text { "My training allowed me to be compassionate, understanding of multicultural aspect of patient care. } \\
\text { In my current position, there are mixed ethnicities, first and second-generation immigrants " } \\
\text { " "Psychosocial rounds dramatically changed my ability to sympathize/empathize/connect to patients and situations. } \\
\text { I am able to channel a calmness that is often elusive in other parts of my life and for other clinicians when faced with a } \\
\text { difficult situation for patients." } \\
\text { " The insistence that all of my patients be viewed as people, ability to meet with a "difficult patient" and see a } \\
\text { challenge and an opportunity rather than a hassle, and insistence that the education of our residents is as important as } \\
\text { anything else that we do. I try to bring this to the teaching that I do currently." } \\
\text { "The time that we spent during our PC blocks doing research, learning to lobby, and thinking about psychosocial } \\
\text { contributors to health were very unique. My preparation as a well-rounded physician meant for vastly different } \\
\text { interactions with my patients, their families, and my interns throughout my years." } \\
\text { "It imbued me with values and ideals, more than anything: care of the patient, especially those poor and } \\
\text { disadvantaged; a healthy skepticism for and admiration of medical evidence." }\end{array}$ \\
\hline $\begin{array}{l}\text { Challenges to patient- } \\
\text { centered care }\end{array}$ & $\begin{array}{l}\text { " "The advocacy/policy part is something I would aspire to do but as a young clinician-educator it is hard to } \\
\text { incorporate" } \\
\text { " "Continuity of care - this has become more difficult to achieve as our health care system evolves, } \\
\text { especially in major metropolitan areas." } \\
\text { " Maintaining a "purity" of primary care practice - not influenced by time pressures, reimbursements, metric } \\
\text { achievements, and politics" }\end{array}$ \\
\hline Preparedness of practice & $\begin{array}{l}\text { - "In retrospect, I think I was just as prepared as they were, } \\
\text { although I think my confidence could have been a little better." } \\
\text { " "I think I had a better approach to difficult patients and somatizing patients than my colleagues" } \\
\text { - "While I feel that the PC residency prepared me ideologically for primary care, } \\
\text { I am not sure that it prepared me to make a decision about what type of primary care I might practice." } \\
\text { "I think that we did not have enough exposure to electives - particularly sub-specialties of internal medicine that } \\
\text { would be helpful as a general internist" } \\
\text { - "Delegating tasks and coordinating information - it was hard to be viewed as team leader early in my career" }\end{array}$ \\
\hline
\end{tabular}


Supply and Population Mortality. JAMA Internal Medicine. 2019;179(4):506-14. https://doi.org/10.1001/jamainternmed.2018.7624

3. Zabar S, Wallach A, Kalet A. The Future of Primary Care in the United States Depends on Payment ReformThe Future of US Primary Care Depends on Payment ReformResearch. JAMA Internal Medicine. 2019;179(4):515-6. https://doi.org/10.1001/jamainternmed.2018.7623

4. Lipkin M, Zabar SR, Kalet AL, Laponis R, Kachur E, Anderson M, et al. Two decades of Title VII support of a primary care residency: process and outcomes. Acad Med. 2008;83(11):1064-70. https://doi.org/10.1097/ ACM.0b013e31818928ab
5. Dyrbye LN, Varkey P, Boone SL, Satele DV, Sloan JA, Shanafelt TD. Physician Satisfaction and Burnout at Different Career Stages. Mayo Clinic Proceedings. 2013;88(12):1358-67. https://doi.org/10.1016/j.mayocp. 2013.07.016

Publisher's Note Springer Nature remains neutral with regard to jurisdictional claims in published maps and institutional affiliations. 